\title{
África do Sul, humor e transgressão: a representação de Jacob Zuma no traço de Zapiro
}

\author{
Renata de Paula dos Santos
}

Graduada em Comunicação Social - Jornalismo pela Universidade Estadual de Londrina. Especialista em Comunicação Popular e Comunitária e Mestranda em Comunicação pela mesma instituição. Bolsista da Capes.

\begin{abstract}
RESUMO
O objetivo deste artigo é fazer uma análise da representação imagética de Jacob Zuma, presidente sul-africano desde 2009. Com uma vida pessoal controversa, o líder acumula processos contra órgãos de imprensa. O discurso chárgico, como se sabe, é um recurso que vem sendo amplamente utilizado para provocar constrangimentos em figuras públicas notórias, pondo muitas vezes em cheque a credibilidade de pessoas proeminentes. A partir de charges de Jonathan Shapiro, conhecido pelo pseudônimo de Zapiro, empreendemos uma análise discursiva, baseada fundamentalmente na imagem, com o propósito de verificar como as charges relacionadas ao presidente desconstroem o discurso oficial sul-africano. Para problematizar a questão sul-africana foram utilizados os autores Carlin (2009), Magnoli (1998) e Marinovich e Silva (2003). No que concerne à charge e seu alcance político, de caráter constestatório, destacam-se as contribuições de Romualdo (2002) e Teixeira (2005). Como métodos de pesquisa foram utilizados a análise do discurso chárgico e pesquisas históricas e bibliográficas. Desse corpus específico, pode-se chegar a avaliações mais abrangentes a respeito da política contemporânea da África do Sul, o que faz com que o trabalho transite nos territórios da comunicação e da história.

Palavras-chave: Charges; Discursos imagéticos; Jacob Zuma.
\end{abstract}

\begin{abstract}
The objective of this paper is to analyze the imagery representation of Jacob Zuma, President of South Africa since 2009. With a controversial personal life, the leader builds cases against the press. The cartoon's discourse, as we know, is a feature that has been widely used to cause embarrassment in public figures notorious, often putting in check the credibility of prominent people. From cartoons Jonathan Shapiro, known by the pseudonym Zapiro, we undertook a discourse analysis, based mainly on image, in order to see how the charges related to deconstruct the official president of South Africa. To discuss the issue South African authors were used Carlin (2009), Magnoli (1998) and Marinovich and Silva (2003). Regarding the cartoons and its political significance, character of contestation, we highlight the contributions of Romualdo (2002) and Teixeira (2005). As research methods were used cartoon's discourse analysis and historical research and literature. In this specific corpus, we can reach more comprehensive reviews about the contemporary politics of South Africa, which makes transit work in the territories of communication and history.
\end{abstract}

Keywords: Charges; Speeches imagistic; Jacob Zuma. 


\section{Charge - $O$ humor jornalístico}

A charge é um elemento de comunicação bastante difundido. O formato jornalístico - composto por texto e imagem - tem a função de dissertar sobre assuntos de grande relevância, sobretudo no campo da política e da economia. A charge é mais informal do que os outros gêneros de comunicação. Com um tom de comentário, o chargista dá voz a opiniões que não são transmitidas nos textos escritos, nem mesmo nos orais. Para Luiz Guilherme Sodré Teixeira (2005), a charge é a trapaça da razão. O formato age como um porta-voz da sociedade, ao mesmo tempo em que transgride as normas, questiona as regras e coloca em xeque o senso comum.

Rafael Souza Silva no livro "Gêneros Jornalísticos na Folha de S. Paulo" (1992), organizado por José Marques de Melo, comenta que o chargista é um dos profissionais que melhor precisa conhecer e compreender as nuances e características do momento social e político do país, já que a partir deste dados, ele vai proferir - e transferir para o traço - os seus juízos de valor. A charge traz à tona questionamentos muito particulares do artista que a produziu. Esta condição pode ser exemplificada pelo cartunista aqui analisado: Jonathan Shapiro.

Zapiro, pseudônimo com o qual assina as charges, é o cartunista sul-africano mais conhecido no exterior. Em meados da década de 1990, começou a trabalhar nos principais jornais do seu país. Com uma atuação de relevância durante os últimos anos do apartheid, ele se destacou por suas ácidas críticas aos chefes do partido africânder e ao sistema de segregação racial. Recentemente Zapiro foi acusado pelo Congresso Nacional Africano (CNA), partido que está no comando do país desde 1994, por criar charges com argumentos racistas. A discussão teve seu ápice em 2008, com a publicação de formatos que questionavam a postura do então candidato à presidência da República pelo CNA, Jacob Zuma. E, principalmente, suas tentativas de apagar as acusações de corrupção e estupro que respondia. No entanto, no pleito eleitoral de 2009, Zuma foi o vencedor.

O processo entre o presidente e o chargista se arrastou por quatro anos, até que, em novembro de 2012, Jacob Zuma desistiu da batalha judicial. O fato foi visto pela opinião pública interna como uma vitória da liberdade de expressão, pois as pressões governamentais não impediram que trabalhos semelhantes ao de Zapiro fossem realizados. Mais do que a interpretação dos fatos que estão inseridos no corpo do jornal, o trabalho de Zapiro é marcado pela sua forma de ver o mundo e também pela opinião das pessoas com quem ele conversa, discute, divide opiniões... A charge, em conceitos bakhthinianos, é um formato polifônico e dialógico, já que traz em sua constituição inúmeras vozes. Para Bakhtin, conforme destaca Robert Stam (1992), a linguagem é mais do que um sistema abstrato, é também uma construção coletiva composta por inúmeros autores. A linguagem é construída a partir de diálogos cumulativos. Ainda em Bakhtin, mas no texto "Marxismo e Filosofia da Linguagem", destaca-se que todo signo é ideológico. E a partir desta premissa, pondera-se que os signos são capazes de refletir ou de refratar dada realidade. $\mathrm{Na}$ charge esses conceitos podem ser percebidos. Por meio dos textos visuais e verbais, o chargista tem a chance de criticar ou de elogiar determinado fato ou personalidade.

Em Edson Carlos Romualdo (2000), a charge é tratada como um texto, composto por elementos linguísticos e visuais, que tece críticas a personagens, fatos ou acontecimentos políticos. Destaca-se que: "Os textos chárgicos transmitem informações (informatividade), utilizando o sistema pictórico, ou sincreticamente o pictórico e o verbal. Os chargistas colocam neles suas opiniões, suas críticas a personagens e fatos políticos (intencionalidade)." (ROMUALDO, 2000, p.18). Já em Silva (1992), o elemento é descrito como um desenho de ataque. O formato não tem a intenção de apenas ilustrar os textos mais relevantes distribuídos ao longo do periódico, mas o de suscitar novas interpretações, de estimular novos olhares. A charge, muitas vezes, pode ser um elemento de crítica ao próprio jornal em que ela se insere, apontando falhas ou omissões na cobertura jornalística. É por isso que alguns autores preferem nomear este elemento como a opinião ilustrada ou o editorial gráfico. Para Teixeira (2005), a charge produz um editorial às avessas: ainda que compartilhe de um espaço privilegiado dentro da esfera jornalística, ele não se justifica como o lugar da (nobre) opinião - marcado pela seriedade e solenidade. A charge é mais informal e subjetiva.

Composta por textos e piadas ambíguas, o formato concerne, por meio do humor e dos traços hiperbólicos, a sua intenção. Percebese a caricatura como um dos elementos estruturais deste formato:

É no desenho que a caricatura se firma como gênero jornalístico de humor cujo objetivo principal é a crítica e a sátira social e política. A caricatura é a sátira desenhada e, como desenho humorístico, nem sempre corresponde a uma intenção agressiva e destruidora. Muitas vezes ela perde essa função destruidora para servir como instrumento de destruidora para servir como instrumento de públiço, cujo objetivo é tornar rápida a du púbicida a sua popularizaça.o. E o caso de muitos artistas e polricos inciantes quese tor un conhecidos através dos traços satíricos utilizados pelos
A distorção caricatural é simbólica e, por meio da desproporção, leva ao ridículo. O exagero é proposital e tem o intuito de colocar em evidência os defeitos de quem está representado. Em Propp (1992), a comicidade é entendida como a apresentação dos defeitos da natureza espiritual por meio da deformação da natureza física. Percebese, portanto, uma correlação entre o que é visível (natureza física) e invisível (natureza espiritual). Por meio das deformações, os chargistas buscam colocar a nu o que estava escondido.

Qual a intenção do chargista quando representa um homem com traços animalizados? Ofensa? Crítica? Repúdio? Mudança social? Talvez todas essas características e até outras mais. São essas interpretações humorísticas que provocam o riso no leitor e se voltam direto à personalidade representada. Para o semioticista Umberto Eco (1989), o humor é transgressão. "Así, la realización del humor funciona como una forma de crítica social. El humor simpre es, si no metalingüístico, si metasemiótico: a través del linguaje verbal o otro sistema de signos, pone en duda otros códigos culturales." (ECO, 1989, p.19). Para o autor, o humor tem a função social de derrubar as leis, de apontar outras direções. Ou seja "si hay una possibilidad de transgressión, está más bien en el humor que en lo cómico.". (ECO, 1989, p.19).

Para Propp (1992), o riso de zombaria também se enquadra como um meio para contestação social. Ainda que o intuito deste teórico não tenha sido o de pensar este conceito no universo chárgico, nós nos propomos a isto. $\mathrm{Na}$ charge, como apregoa Propp (1992, p.46), "o riso é uma arma de destruição: ele destrói a falsa autoridade e a falsa grandeza daqueles que são submetidos ao escárnio.". 


\section{2. África do Sul e apartheid - a questão da} identidade

Entre os anos de 1948 e 1994, a Áfric do Sul foi governada por um regime político com características altamente particulares. O apartheid era um sistema de governo regido pela minoria branca, inspirado nos ideais nazistas e na supremacia racial. Com uma legislação altamente específica o regime dividiu a sociedade sul-africana levando em consideração critérios raciais e linguísticos. O apartheid foi um produto histórico que marchou na contramão dos ideais de modernidade. Por sua estrutura pautada na diferenciação entre brancos não brancos, este modelo de governo criou um quadro de conflitos internos altamente específicos. Em meados da década de 1950 durante seus primeiros anos de implantação o apartheid foi visto pelo Estado branco como um eficiente meio para a domesticação submissão da força de trabalho, inserida e alicerçada no modelo capitalista. (MAGNOLI, 1998)

A política segregacionista sul-africana representou o domínio da minoria branca (de origem europeia, sobretudo, inglese e holandeses) sobre os negros, maioria dos habitantes da África do Sul, mestiços e asiáticos (principalmente os indianos) Disposições como a "Lei de Proibição de Casamentos Mistos ("Prohibition of Mixed Marriages Act", de 1949)", a "Lei de Registro da População ("Population Registration Act", de 1950)", a "Lei das Áreas de Grupo" ("Group Áreas Act", de 1950, mas posta em vigor dezesseis anos mais tarde) e "Lei da Circulação de Nativos" "Native Act", de 1952), para citar apenas algun pontos da legislação sul-africana durante regime de segregação, tinham o intuito de impedir o contato entre brancos e negros.
O objetivo era dividir o país em áreas raciais independentes. A região de brancos ocuparia o centro sul-africano e a população negra seria distribuída, de acordo com uma classificação étnica, nas periferias. Desta forma, os negros se encontrariam com os brancos apenas nas relações trabalhistas, já que as relações afetivas entre casais interraciais eram proibidas e o país ofertava serviços públicos separados. Desta forma, a troca de experiências e expressões culturais não ocorreria.

Durante o apartheid, os sujeitos não brancos eram retirados da condição de sulafricanos. A Lei de Circulação de Nativos tornava obrigatória a posse de autorização (passe ou passaporte) para a circulação em territórios em que não habitasse. A fiscalização era realizada pela polícia, como meio de controlar o fluxo de pessoas em outras regiões. Todas as medidas restritivas do apartheid diziam respeito à submissão dos negros ao governo branco: apenas a população branca tinha o direito de goza de plenos direitos políticos e sociais. No entanto, como fica a questão da identidade na África do Sul? Os negros se reconheciam na dupla relação negro e sul-africano? Ou essas caraterísticas identitárias não eram complementares, mas contraditórias?

Woodward (2009) afirma que a identidade é marcada por meio de símbolos: a relação entre o sujeito e as coisas que ele usa ou gosta, por exemplo. A identidade do mexicano é confirmada a partir do seu sombreiro e do brasileiro pelo seu amor ao carnaval e ao futebol. Será? A identidade é relacional, para existir e se legitimar, ela precisa de elementos dissonantes em seu exterior. Ser português, por não ser espanhol. Torcer para Flamengo, por não gostar do Vasco ou dos outros grandes cariocas. Mais do que relações antagônicas, a marcação da identidade ocorre pela diferença. Quando se trata das identidades nacionais, a delimitação recorre à História. A autora afirma que os grupos remontam à árvore genealógica e aos seus antecedentes. Pensando no caso específico da África do Sul, entre os anos de 1648 e 1833, holandeses e ingleses dividiram o território e a posse dos escravos (compostos pela população negra). Remetendo a esta condição, os negros eram percebidos pelos brancos como objetos, sem direitos ou vontades...

No entanto, a relação entre senhor e escravo não é a única hipótese provável quando se percebe $o$ antagonismo entre identidade negra e identidade sul-africana. A própria inspiração nos princípios nazistas é um meio para destacar os brancos (tidos como raça pura e superior) do restante da população do país. Carlin (2009) afirma que os benefícios sociais na África do Sul eram divididos, em ordem decrescente, entre brancos, mestiços, indianos e negros. Tal medida tinha o intuito de deixar os negros à margem da sociedade, ainda que eles representassem a maioria numérica no país. Desta forma, ser negro, mestiço ou asiático era o oposto de ser "sul-africano" (brancos). Kabenguele Munanga (2008) destaca que o apartheid, por meio do afastamento social, não teve o intuito de possibilitar a conservação da identidade dos grupos segregados. Munanga (2008, p. 99) aponta que:

Do nosso ponto de vista, não encontramos sinal de tolerância num regime que, durante quase meio século, manteve separados do berço ao túmulo os brancos e não brancos. Para nós, a chamada tolerância das diferenças raciais e culturais na África do Sul durante o apartheid foi apenas uma estratégia ou um apartheid foi apenas uma estratégia ou um pretexto para legitimar a segregação racial e, negra de seus direitos cívicos e políticos.
Quem aparta e segrega não mostra nenhuma tolerância para conviver com as diferenças.

Tendo em vista o retalhamento geográfico da África do Sul, o apartheid disseminou a intolerância social e dificultou a mobilização política entre os não brancos. É difícil considerar que o sistema tenha propiciado a unidade dos grupos segregados. Considerando apenas a população negra, o Estado organizou uma fragmentação em dez grupos sociais. Sendo assim, é muito difícil falar em uma identidade negra única, apresentam-se ao menos dez. Como fruto desta fragmentação social destaca-se a Guerra dos Albergues, de 1990 e 1994. Os conflitos entre os negros das etnias xhosas (partidários de Nelson Mandela e do CNA) e zulus (grupo descrito por Carlin [2009] como a direita negra; composto por militantes financiados pelo governo branco) dizimaram cerca de 14 mil pessoas. Apesar do término da política de segregação, a África do Sul ainda registra atualmente inúmeros casos de xenofobia. A este respeito, Magnoli (1998) pontua que:

[...] o apartheid não se transformará do dia para a noite em um mero episodio concernente ao passado histórico, pois as estruturas sociais e os símbolos que gerou continuarão envenenando as relações políticas do país por muito tempo. O espectro de uma "guerra étnica" entre os negros sul-africanos continuará a rondar as townships e as favelas, como se os pajés da Broederdond e os "engenheiros de etnias" Broederdond e os "engenheiros de etnias" do Partido Nacional tivessem lançado uma maldição sobre o futuro dos inimigos da sua
tribo. (MAGNOLI, 1998, p. 79).

\section{Nelson Mandela e CNA: expoentes da resistência}

Nelson Mandela é um dos nomes mais conhecidos no combate à segregação 
racial na África do Sul. Militante político desde a juventude, foi preso na década de 1960, acusado de traição e condenado à prisão perpétua. Ao lado do líder negro sempre esteve o CNA, principal partido de oposição do país. Na década de 1980 com o agravamento da crise política e a intensificação da pressão internacional, governo branco iniciou um processo de negociação com Mandela. Em 1985, o então presidente sul-africano Pieter $\mathrm{W}$. Botha ofereceu a liberdade ao militante, em troca do fim da oposição negra. A oferta fo publicamente negada por Nelson Mandela em um discurso lido por uma de suas filhas. No entanto, o término do apartheid era um processo irreversível e em 11 de fevereiro de 1990, o líder negro saiu da prisão.

No mesmo ano, o CNA iniciou o processo de transição para a democracia multirracial. A abertura política foi marcada por muita violência e oposição do Estado branco. As primeiras eleições multirraciais foram realizadas em abril de 1994. A disputa eleitoral contou com 19 partidos e cerca de 22 milhões de sul-africanos (maiores de 18 anos) se inscreveram para participar do processo eleitoral. O pleito elegeu Nelson Mandela para um mandato de cinco anos. De acordo com o jornalista americano John Carlin (2009), o desafio do governo do líder negro não foi a construção de grandes obras ou a aceleração do crescimento econômico mas a criação de uma base democrática sólida que evitasse a tomada do poder, a instauração de uma ditadura ou até mesmo uma guerra civil.

Desde 1994 até 2009, ano da última eleição majoritária, a África do Sul fo presidida por negros, membros do CNA (SANTOS, 2010). No entanto, os líderes estatais pós-Mandela emplacaram mandatos polêmicos e acusações de corrupção. Thabo
Mbeki foi o segundo presidente negro da África do Sul, sucedeu Mandela na chefia do executivo. Reeleito pelos sul-africanos, Mbek presidiu o país entre 1999 e 2008, mas renunciou ao cargo por pressões do próprio partido após ser acusado de corrupção.

As eleições de 2009 foram vencidas pelo também ex-militante negro Jacob Zuma. Apesar de ter usado seu passado de atuação política como triunfo eleitoral, o candidato de origem zulu sofreu baixas significativas no interior do próprio partido e entre as principais lideranças antiapartheid, como o arcebispo anglicano emérito da Cidade do Cabo, Desmond Tutu. Zuma acumula as acusações de desvio de dinheiro, estupro, corrupção, fraude, extorsão e de ter mandado matar o suposto amante de uma de suas esposas. Em 2012, o presidente voltou a ser notícia na imprensa internacional ao anunciar o seu sexto casamento. A postura de Jacob Zuma é frequentemente criticada pelos veículos de comunicação, tendo em vista que a África do Sul é o país com o maior número de infectados com o vírus da AIDS no mundo. Em uma pesquisa de 2007, publicada pela revista "National Geographic" em junho de 2010, a nação africana aparecia com 5,7 milhões de portadores da doença - ou seja, $17 \%$ dos soros positivos de todo o mundo eram sul-africanos.

Desde o afastamento de Nelson Mandela da vida pública, o CNA tem perdido força e credibilidade em toda a África do Sul. Além disso, o país ainda sofre com a desigualdade social construída em mais de quatro décadas de segregação. As tentativas do partido de cercear a atividade da imprensa (no episódio de Zapiro) foram interpretadas pelos veículos de comunicação nacionais e internacionais como um atentado à democracia.

\section{Pós-modernidade, descentralização} histórica e os velhos preconceitos

Ao escrever sobre a cultura pós-moderna, Steven Connor (1992) faz uma análise de autores que se destacaram na abordagem do tema, entre eles o marxista americano Fredric Jameson, conhecido pela premissa de que a pós-modernidade se trata da dissolução do econômico na cultura. Para Jameson, uma das principais características da pós-modernidade é o apagamento do sentido da história. A sociedade está inserida em um estado de presente perpétuo. O momento global é agravado pela intensificação do capitalismo e de suas formas de atuação e de penetração no campo social.

Várias são as formas de conceituar atual momento histórico: modernidade líquida, pós-modernidade, modernidade tardia... No entanto, este fenômeno social é descrito como a quebra da historicidade e da cronologia, as crises nas representações, o esgotamento da racionalidade e até mesmo como o tempo catastrófico. Não é possível mais estabelecer um sentido para o vivido. No entanto, em uma realidade onde tudo é líquido, sem profundidade e passageiro, como fica a questão dos preconceitos, da identidade, da representação e do racismo?

Se o pós-moderno global representa uma abertura ambigua para a diferença e para as margens faz com que certo tipo de descentramento da narrativa ocidental se torne provável, ele é acompanhado por uma reação que vem do âmago das políticas culturais: a resistência agressiva à diferença; a tentativa de restaurar o cânone da civilização ocidental; o ataque direto e indireto ao multiculturalismo: o retorno às grandes narrativas da história, da língua e da literatura (os três grandes pilares de sustentação da identidade e da cultura nacionais): a defesa do absolutismo étnico, de um racismo cultural que marcou a eras Thatchere Regan; e as novas xenfobias que stão prestes a subjugar a Europa. (HALL 2003, p. 339-340).

Aplicando o que foi descrito por Hall (2003) no contexto do apartheid sul-africano, nos deparamos com esta busca incansável por reestabelecer a sociedade pura, composta apenas por brancos. Para o teórico jamaicano, tal recurso prima por des-historicizar a diferença e ainda confundir o que é histórico e cultural com as condições naturais, biológicas e genéticas (HALL, 2003). O preconceito é algo cultural, externo. Como já afirmou Nelson Mandela, ninguém nasce odiando outra pessoa por qualquer motivo, mas é ensinado a ter este sentimento. Em Woodward (2009), a identidade é apresentada como algo culturalmente moldado. Desta forma: Pode-se levantar questões sobre o poder da significados são preferidos relativemente significados sao preferidos relativamente a outros. Todas as práticas de significação que produzem significados envolvem relações quem é incluído quem é incluido e quem é excluído. A cultura molda a identidade ao dar sentido à experiência e ao tornar possível optar, entre as várias identidades possíveis por um modo específico de subjetividade [...] Somos constrangidos, entretanto, não apenas pela gama de possibilidades que a cultura oferece, isto é, pela variedade de representações simbólicas, mas também pelas relações sociais. (WOODWARD, 2009, p. 19)

Para Shohat e Stam (2006), o racismo é um ponto de vista histórico, reforçado pelas influências do colonialismo. Os autores destacam que: "As vítimas mais óbvias do racismo são aquelas cujas identidades foram forjadas no caldeirão colonial: os africanos, os asiáticos e os povos nativos das Américas" (SHOHAT; STAM, 2006, p. 45). O pensamento racial é fruto da cultura colonialista, fortificado pela ideia de superioridade ontológica. Mais do que 
o desrespeito individual a uma pessoa por levar em conta a cor de sua pele, religião ou opção sexual, qualquer tipo de pensamento preconceituoso apresenta-se como um entrave ao desenvolvimento da sociedade. A intolerância e o desrespeito marcham na contramão dos avanços sociais. Ao discorrer especificamente sobre o racismo, os dois autores o classificam como um movimento agressivo e tautológico. As categorias raciais são divisões culturais que se consolidaram e se legitimaram no curso da história.

$O$ racismo envolve um duplo movimento de agressão e narcisismo; o insulto ao acusado acompanhado por um elogio ao acusador. pensamento racista é tautológico e circular: somos poderosos porque estamos certos, estamos certos porque somos poderosos. Também é essencialista, a-histórico metafísico, pois projeta a diferença através da temporalidade histórica: "Eles são todos assim, e assim continuarão sendo

As categorias raciais não são naturais ou absolutas: são construções relativas específicas, categorias narrativas engendradas por processos históricos de diferenciação. A categorização de uma mesma pessoa pode variar com o tempo, o local e o contexto. Também a autodefinição subjetiva e mobilizacão olítica podem sabotardefinicõos rígidas. (SHOHAT; STAM, 2006, p.45-46).

\section{A contribuição da charge para o resgate histórico}

A partir da contribuição dos distintos teóricos aqui apresentados, o nosso interesse é analisar o discurso chárgico sobre três frentes: a charge como linguagem, como discurso do chargista e a recepção do discurso. Essas categorias são aplicadas a três charges de Zapiro de 2006 e 2008. Os formato discorrem sobre a política contemporânea com críticas ácidas ao presidente Jacob Zuma.

A figura 1 - Zuma sues Zapiro - fol publicada no "Independent Newspapers" em julho de 2006.

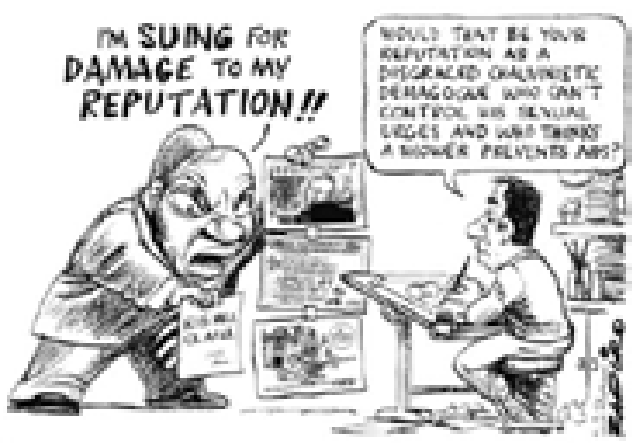

Fig 1. Zuma sues Zapiro (2006), Zapiro Africartoons

Neste ano, o então candidato à presidência da República foi acusado de estuprar a filha de um amigo. A jovem possui o vírus da AIDS e trabalha em um projeto com o objetivo de conscientizar a população da gravidade da doença. Zuma se defendeu dizendo que a mulher utilizava roupas que o provocavam e que ele, como um viril homem zulu, cumpriu o seu papel. Quando indagado sobre o crime que havia cometido, ele afirmou que a relação foi consensual, mas que ele não usou preservativo porque uma ducha posterior ao ato sexual foi o suficiente para protegê-lo da contaminação. A jovem definiu o fato como um estupro terrível.

A charge enquanto linguagem utiliza das palavras e das formas para criticar o sistema político da África do Sul e o seu chefe de Estado. O formato é metalinguístico, já que o próprio caricaturista se insere no quadro. Como já foi mencionado anteriormente, em Bakhtin é possível compreender a charge como dialógica. Ainda que a assinatura e que os eventuais prejuízos legais que este argumento poderia causar fossem creditados diretamente a Zapiro, a opinião é coletiva e construída a partir da interação com outros sujeitos. Teixeira (2005) destaca que a charge traz à tona aspectos de Jacob Zuma que ele pretende esconder.

No plano da crítica, podemos perceber que as três figuras escolhidas para esta análise trazem em si muito da relação de gênero na África do Sul. A utilização do suposto estupro como um argumento chárgico levanta uma discussão sobre a instabilidade das relações sociais no país. Acredita-se que na visão de Zapiro, a vitória de Zuma, um candidato acusado de ter cometido um estupro, coloca em xeque os esforços para reduzir o índice de estupros e de crimes violentos no país. A África do Sul possui uma das maiores taxas de estupros do mundo. Em 2007, foram registrados 76 casos para cada 100 mil habitantes, mais que o dobro dos casos registrados pelos Estados Unidos - $30 \mathrm{em}$ cada 100 mil.

Enquanto discurso de Zapiro, a charge destaca-se por seus argumentos políticos bem consolidados. Ao se inserir na representação, o chargista deixa claro a leitura que ele faz de Jacob Zuma. Para Bakhtin (1997), todo signo é ideológico, e esse conceito pode ser percebido no argumento construído pelo chargista: na caricatura de Zuma, é possível perceber que o personagem foi construído de forma alterada, com muita raiva. A presença de páginas de jornais tem o intuito de confirmar o que ele grita, que sua reputação tem sido sistematicamente atacada. Ainda no que diz respeito à fala do político, algumas palavras foram grafadas em negrito, com o intuito de reforçar o discurso, enfatizar. A charge rendeu um processo a Zapiro no valor inicial de 15 mil rands, entretanto, posteriormente o valor foi reduzido.

Já a representação do chargista tem o intuito de reforçar completamente o contrário. Na figura (1), enquanto ele responde, de maneira calma (sem nenhuma alteração na grafia do discurso), à afirmação de Zuma, o chargista faz mais uma caricatura do chefe de Estado. Ou seja, ele continua seu trabalho e tem certeza do que está fazendo, não se sente abalado pela raiva do presidente ou pela ameaça do processo.

Enquanto recepção, podemos destacar três possibilidades conforme enumera Stuart Hall (2003): decodificação de dominância, onde há a reprodução dos valores da charge (crítica a Jacob Zuma); decodificação de resistência, rejeição às ideias disseminadas pelo formato (desconsiderar as críticas de Zapiro) e decodificação de negociação simbólica (perdas e ganhos para os dois ados). Neste caso, a partir da repercussão das charges e até mesmo do posicionamento de Zuma e do CNA podemos intuir que a decodificação tenha sido de dominância. No entanto, a dominância, neste caso, apresentase como crítica ao discurso estatal. O discurso da charge é o discurso da contra-hegemonia. A charge independente do segmento a que seu argumento se valha, tem sempre a intenção de persuadir, de convencer o leitor daquilo que apresenta.

A figura 2 - "AIDS Message" - também foi publicada no "Independent Newspapers". A veiculação ocorreu em setembro de 2006. Esta charge ainda é uma repercussão de alguns argumentos utilizados na anterior (Figura 1), sobretudo a afirmação do político de que uma ducha após o ato sexual é suficiente para evitar a contaminação pelo vírus da AIDS. A figura 2 também representa uma nova fase da representação chárgica de Jacob Zuma. Desde que ele afirmou que um banho é suficiente para evitar a AIDS, Zapiro tem feito a caricatura do líder negro com um chuveiro sobre a cabeça. O chargista, que fez o primeiro "Zuma shower" em 2006, classificou em uma entrevista a opinião e postura do político como absurdas. 


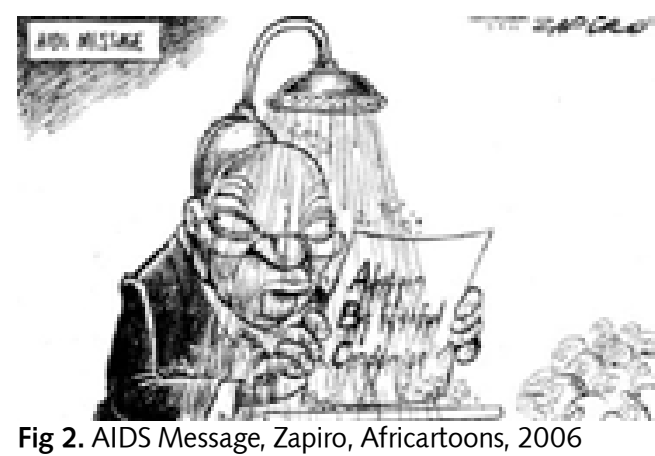

A charge enquanto elemento de comunicação questiona a vida sexual de Jacob Zuma ao mesmo tempo em que coment sobre a intensa disseminação da doença no país. A carta, com os dizeres: abstain (evitar) be faithful (ser fiel) e condomise (camisinha), traz lições para a vida pública e privada do líder sul-africano. Zuma é representado com um terno, o que reforça sua autoridade enquanto político influente do país, já que nesta época ele ainda não era chefe de Estado.

argumento é relativamente simples, mas é enfatizado pela presença de populare no canto direito da imagem (figura 2). Acredita-se que os rostos realçam a sensação de desconfiança quanto à postura de Zuma em relação a um assunto tão sério. $A$ composição passa a ideia de que esse seja um pronunciamento oficial, um discurso político.

Assim como na charge anterior (figura 1), acredita-se que esta mensagem tenha alcançado uma decodificação de dominância no seio da sociedade. Mais uma vez esta hipótese está baseada nas ações estatais para impedir argumentos como estes. Considerase que as figuras 1 e 2 estabeleçam um crítica ao discurso machista dominante na África do Sul. Na acusação do suposto estupro há a descrição do sexo de maneiras distintas, enquanto para Zuma foi consensual a jovem destacou como uma violência. No entanto, a afirmação do político ao dize que cumpriu o seu papel enquanto um "viril homem zulu" traz à tona traços de machismo e uma classificação da mulher como inferior ao homem.

A última charge (figura 3) escolhida para compor esta análise foi publicada em setembro de 2008 no "Sunday Times". O nome do desenho é "The Rape of Justice". Esta charge foi vista como agressiva pelo CNA e por Jacob Zuma e rendeu mais um processo contra Zapiro. A ação judicial foi retirada em 2012 pelo presidente. Algumas lideranças políticas consideram que a atitude de Zuma foi uma jogada para que sua figura não se enfraquecesse ainda mais no interior do partido.

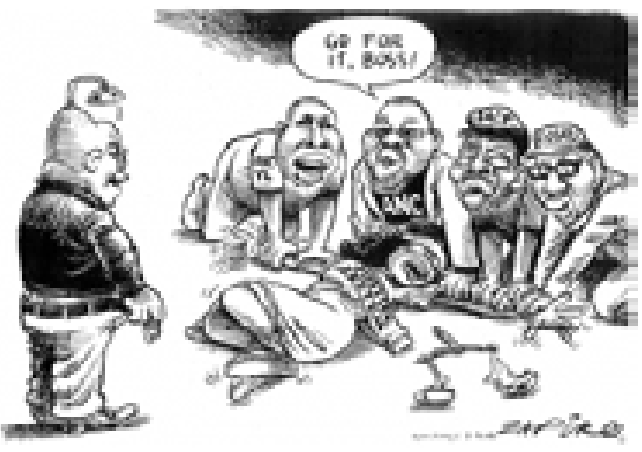

Fig 3. The Rape of Justice, Zapiro, Africartoons

De acordo com o próprio chargista, o argumento do desenho é o poder que Zuma tem sobre a justiça. Ele foi inocentado de denúncias de corrupção e também de estupro, o que garantiu sua candidatura à presidência. No entanto, a ideia de violar a justiça não foi criada por Zapiro. Em 2006 este argumento foi construído por John Curtis. O desenho foi feito no momento em que Zuma era julgado sobre a acusação de estupro.

No entanto, a releitura foi tida como genial pela imprensa sul-africana. Após esse argumento, outros foram construídos por ele e por outros chargistas com a ideia de violação da justiça. Em "The Rape of Justice", o sistema judiciário é humanizado, já que está representado como uma mulher (o que também pode remeter às relações de gênero). A imagem utiliza de pontos já presentes no paradigma do leitor sul-africano quando o assunto é Jacob Zuma, a acusação de estupro de 2006.

Ainda que o político esteja representado de lado, é possível perceber um leve sorriso (satisfação) em sua face. $\mathrm{O}$ ato de abrir a calça é o que sugere a violência sexual, já que a mulher aparece imobilizada por vários homens. E são estes personagens, representantes políticos de destaque no país, que estendem a crítica ao sistema. A frase: Go for it, boss alude à conivência com o crime.

Um ponto que nos permite considerar que, assim como nas charges anteriores (figuras 1 e 2), a recepção desta imagem favoreceu a crítica a Zuma foram as ações do governo para tentar coibir a publicação de argumentos parecidos. Representar um político de destaque no país em uma situação comprometedora é uma decisão de muita coragem.

\section{Primeiros passos. Novos caminhos...}

Mais do que um ensaio, este texto é uma tentativa de utilizar perspectivas teóricas discutidas no Programa de Pós-Graduação em Comunicação na UEL na análise chárgica. Mais do que um ponto de chegada, é, na verdade, um ponto de partida. A proposta é uma tentativa, um primeiro contato.

Foi possível perceber que a charge tem a função de mostrar aquilo que estava escondido. O formato busca, por meio do humor, construir uma crítica bem estruturada nos campos da política e da economia.
No caso específico da África do Sul e do cartunista Zapiro destaca-se uma série de charges com argumentos bem consolidados e que causaram impacto no país e no exterior. De acordo com o site Africartoons, a figura 3 - "The Rape of Justice" foi a charge que mais causou polêmica em todo o país.

Considera-se que a charge traz aos leitores outras nuances de Jacob Zuma, já que as charges levantam questões que não são apresentadas pelo discurso oficial. É impossível analisar a história sul-africana sem mencionar o apartheid e seus efeitos sociais. Por mais que o mandato de Zuma não tenha registros de segregação, a democracia multirracial ainda é recente e apresenta uma série de fragilidades. Os atos apresentados por Zapiro, em forma de desenho, representam um empecilho no desenvolvimento do país que ainda sofre as consequências das mais de quatro décadas de atitudes racistas.

A questão de gênero percorre as charges presentes neste trabalho e que será analisada com mais afinco em reflexões futuras. Zuma é apontado por Zapiro como um representante do machismo sul-africano. No plano político, a eleição de um político com este perfil pode culminar em um retrocesso ao desenvolvimento social do país. A realidade do país é composta por um número altíssimo de estupros. Outra crítica apresentada ao presidente é a sua postura em relação a AIDS. A falta de preocupação do líder negro com a prevenção é um risco para o país que possui o maior número de pessoas contaminadas no mundo.

Então, o que fazer? Seguir..

\section{Referências Bibliográficas}

BAKHTIN, Mikhail. Marxismo e Filosofia da Linguagem: problemas fundamentais 
do Método Sociológico na Ciência da Linguagem. 8. ed. São Paulo: HUCITEC 1997.

CARLIN, John. Conquistando o Inimigo Nelson Mandela e o jogo que uniu a África do Sul. Tradução de Teresa Carneiro. Rio de Janeiro: Sextante, 2009.

CONNOR, Steven. Cultura pós-moderna: introdução às Teorias do Contemporâneo. São Paulo: Edições Loyola, 1992.

ECO, Umberto. Los marcos de la libertad cómica. In: ECO, Umberto; IVANOV, V.V RECTOR, Monica.jCarnaval! México: Fondo de Cultura Económica, 1989.

FULLER, Alexandra. Os filhos de Mandela Revista National Geographic Brasil, n. 123 p.52-81, jun. 2010.

HALL, Stuart. Da diáspora: identidades e mediações culturais. Belo Horizonte: Editora UFMG; Brasília: Representação da UNESCO no Brasil, 2003.

LUZ, Natália da. "Zuma quis me processar", diz cartunista crítico do próximo presidente sul-africano. Disponível em: http://g1.globo. com/Noticias/Mundo/0,,MUL10981045602,00-ZUMA + QUIS + ME + PROCESSA $\mathrm{R}+\mathrm{DIZ}+\mathrm{CARTUNISTA}+\mathrm{CRITICO}+\mathrm{DO}+$ PROXIMO + PRESIDENTE + SULAFRI.html Acesso em: nov. 2012.

MAGNOLI, Demétrio. África do Sul: capitalismo e apartheid. 4. ed. São Paulo: Contexto, 1998.

MARINOVICH, Greg; SILVA, João. O Clube do Bangue-Bangue: instantâneos de uma guerra oculta. Tradução de Manoel
Paulo Ferreira. São Paulo: Companhia das Letras, 2003.

MIANI, Rozinaldo Antonio. Charge: uma prática discursiva e ideológica. Disponíve em: http://www.intercom.org.br/papers/ nacionais/2001/papers/NP16MIANI.PDF. Acesso em: 10 abr. 2011.

As transformações no mundo do trabalho na década de 1990: o olhar atento da charge na imprensa do Sindicato dos Metalúrgicos do ABC paulista. 2005. Tese (Doutorado em História) - Universidade Estadual Paulista, Assis, 2005.

MUNANGA, Kabenguele. Rediscutindo a mestiçagem no Brasil: identidade nacional versus identidade negra. Belo Horizonte: Autêntica, 2008.

PROPP, Vladimir. Comicidade e riso. São Paulo: Ática, 1992.

ROMUALDO, Edson Carlos. Charge jornalística: intertextualidade e polifonia: um estudo de charges da Folha de S. Paulo. Maringá: EDUEM, 2000

SANTOS, Renata de Paula dos. África do Sul e apartheid: análise imagética dos conflitos raciais de 1990 a 1994. 2010. Trabalho de Conclusão de Curso (Graduação em Comunicação Social - Habilitação em Jornalismo) - Universidade Estadual de Londrina, Londrina. 2010.

SHOHAT, Ella; STAM, Robert. Crítica da imagem eurocêntrica. São Paulo: Cosac Naify, 2006.

SILVA, Rafael Souza. Caricatura. In: MELO, José Marques de. Gêneros Jornalísticos na
Folha de S. Paulo. São Paulo: FTD, 1992.

STAM, Robert. Bakhtin: da teoria literária à cultura de massa. São Paulo: Editora Ática, 1992

TEIXEIRA, Luiz Guilherme Sodré. Sentidos do humor, trapaças da razão: a charge. Rio de Janeiro: Casa de Rui Barbosa, 2005.

WOODWARD, Kathryn. Identidade e diferença: uma introdução teórica e conceitual. In: SILVA, Tomaz Tadeu da. Identidade e diferença: a perspectiva dos estudos culturais. Petrópolis: Vozes, 2009. 